\title{
CINQUENTENÁRIO DO CENTRO PAULA SOUZA DOCUMENTO HISTÓRICO NO CENTRO DE MEMÓRIA DA EDUCAÇÃO PROFISSIONAL E TECNOLÓGICA
}

\section{Documento em Destaque: Discurso da "Aula inaugural do Centro Estadual de Educação Tecnológica"}

Maria Lucia Mendes de Carvalho Centro Paula Souza/GEPEMHEP maria.mendes@cps.sp.gov.br

Como curadora do Centro de Memória da Educação Profissional e Tecnológica, criado em 2013, mas em processo de implantação desde 2014, e com o Centro Paula Souza próximo de completar o seu cinquentenário, ter acesso ao documento da "Aula Inaugural do Centro Estadual de Educação Tecnológica São Paulo”, proferida pelo governador Roberto de Abreu Sodré, em 3 de agosto de 1970 (Figura 1 e 2), no auditório da sede da Federação das Indústrias do Estado de São Paulo, cedido pelo Centro de Gestão Documental ao Centro de Memória da Educação Profissional e Tecnológica do Centro Paula Souza, em 14 de junho de 1918 (Figura 3), foi e será de grande valia para pesquisadores de história da educação profissional e tecnológica institucional.

FIGURAS 1 E 2 - Capa e contra capa do documento da Aula Inaugural do Centro Estadual de Educação Tecnológica São Paulo, em 3 de agosto de 1970.
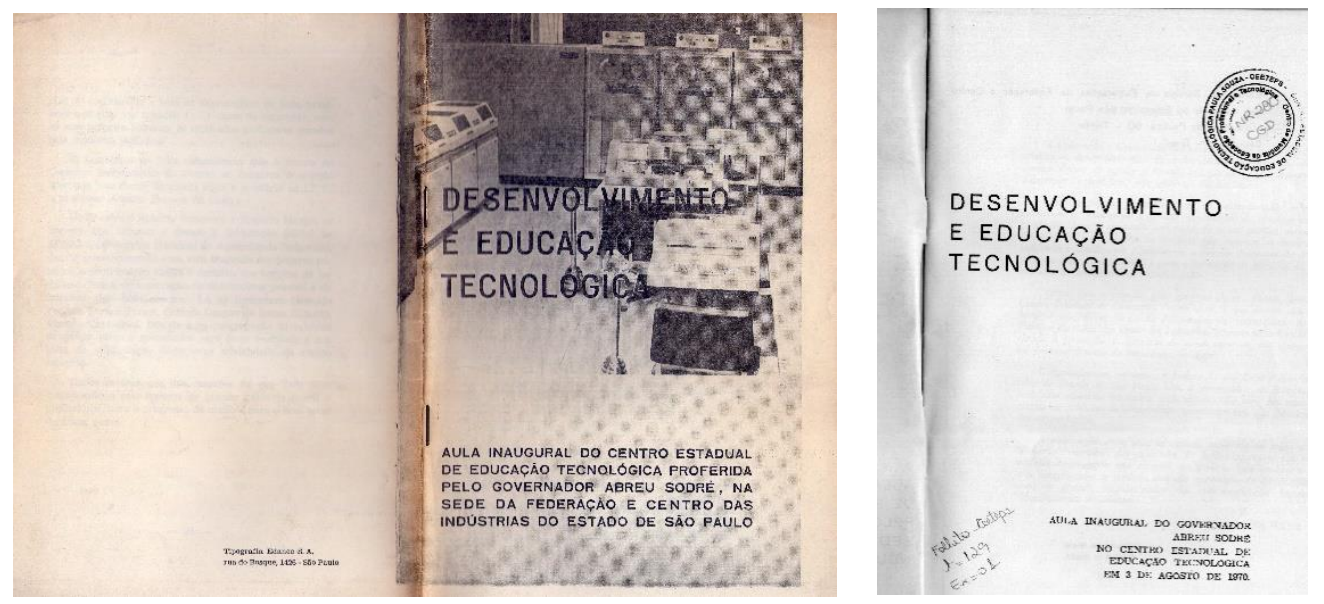

Fonte: Centro de Memória da Educação Profissional e Tecnológica do Centro Paula Souza Fotografia: Maria Lucia Mendes de Carvalho, em 22 de agosto de 2018.

Quanto ao processo de criação do centro de memória institucional, esse tem por objetivo preservar, salvaguardar e divulgar objetos arquivísticos, bibliográficos e museológicos adquiridos 
ou produzidos por gestores, professores e/ou colaboradores da administração central, tendo por proposição promover ações educativas de ensino, pesquisa e extensão, como cursos de formação continuada de docentes que atuam em centros de memória ou com acervos escolares em escolas técnicas (Etec) ou faculdades de tecnologia (Fatec) realizados pela Unidade de Ensino Médio e Técnico (Cetec), assim como propor e organizar oficinas, exposições, encontros e jornadas envolvendo docentes e estudantes para difusão de estudos e pesquisas sobre memórias e história da educação profissional e tecnológica. Um artigo sobre o processo de criação desse centro de memória foi produzido e publicazado em livro institucional (CARVALHO, 2017).

FIGURA 3 - Caixas plásticas com documentos administrativos históricos cedidos pelo Centro de Gestão Documental, em 14 de junho de 2018.

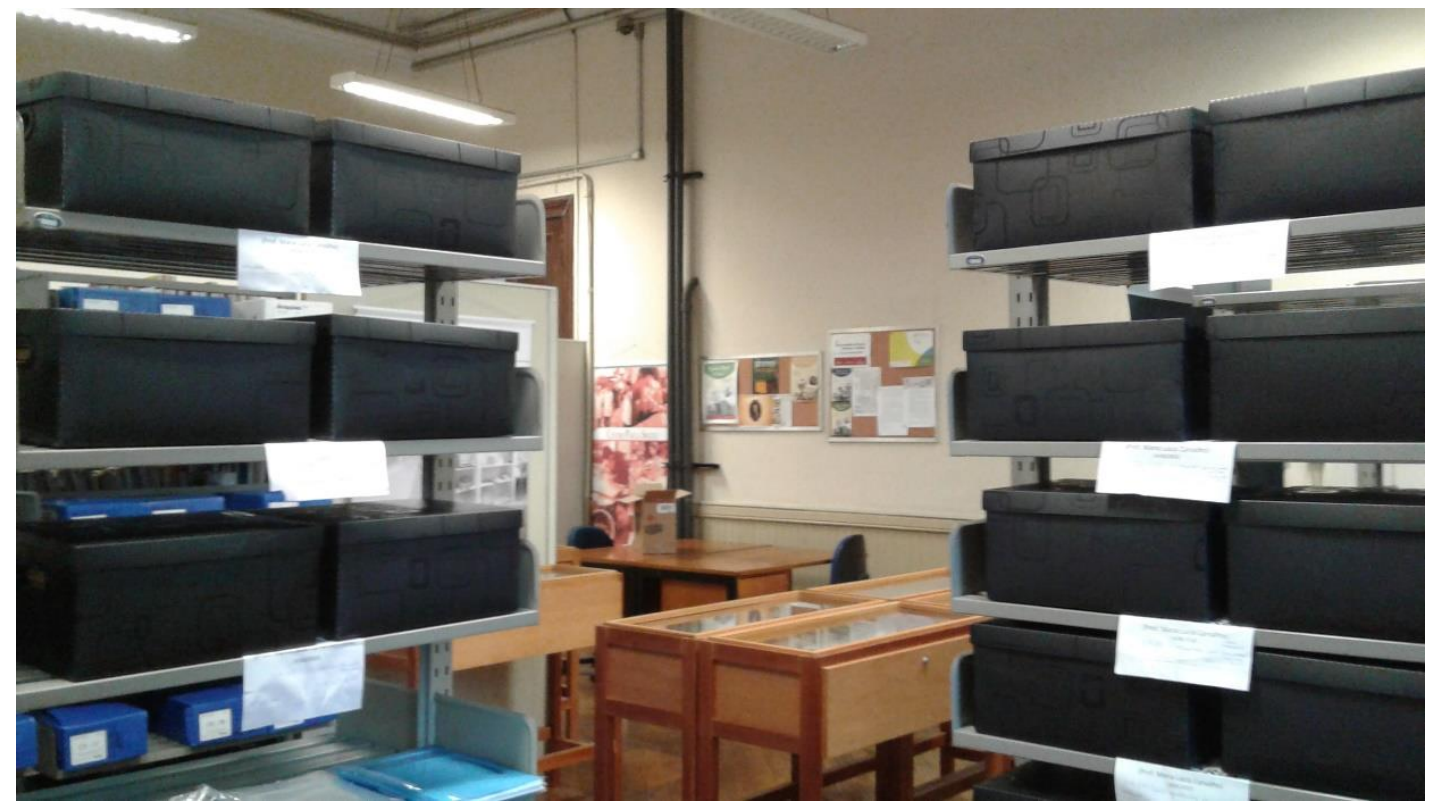

Fonte: Centro de Memória da Educação Profissional e Tecnológica do Centro Paula Souza Fotografia: Maria Lucia Mendes de Carvalho, em 22 de agosto de 2018.

A escolha de implantar o Centro de Memória da Educação Profissional e Tecnológica no Edifício Paula Souza, onde surgiu o Centro Estadual de Educação Tecnológica São Paulo, primeira denominação da atual Faculdade de Tecnologia São Paulo, criado por meio do Decreto-lei de 6 de outubro de 1969, foi devido ao tombamento do conjunto de edifícios da Escola Politécnica.

Esse tombamento foi requerido pelo superintendente do Centro Paula Souza, Marcos Antonio Monteiro, em 1999, ao enviar um ofício ao Secretário da Cultura do Estado de São Paulo, 
e o seu processo finalizado pelo CONDEPHAAT ${ }^{1}$, em 2002. O Edifício Paula Souza foi projetado pelos catedráticos Francisco Ferreira Ramos, Urbano de Vasconcelos e Francisco de Paula Ramos de Azevedo, com diversos Laboratórios, destacando-se o Anfiteatro de Química na parte central do edifício, onde aconteceu a Fundação da Escola Politécnica, em 1893. O tombamento do conjunto da Politécnica, incluiu o Edifício Paula Souza (1895), o Edifício Ramos de Azevedo (1920), o Antigo Laboratório de Hidrodinâmica (1926), os Edifícios Hipolito Pujol e Oscar Machado (1938) e o Edifício Rodolfo Santiago (1944 - 45).

Para participar da $14^{\mathrm{a}}$ Semana Nacional de Museus², cuja temática era "Museus e Paisagens Culturais", comecei a organização realizando uma pesquisa documental no acervo da Biblioteca Nelson Vieira Alves Vianna da Fatec SP, buscando marcas e vestígios dos primeiros dez anos da fundação dessa instituição que funcionou no Edifício Paula Souza. Durante essa pesquisa, encontrei registros iconográficos da cultura escolar em álbum de retratos, e com essas imagens preparei a palestra "Olhar sobre as transformações nas paisagens de um patrimônio cultural: o Edifício Paula Souza e seus arredores (SP)”, ministrada a estudantes e professores no Anfiteatro de Química, atual sala 13P, nesse edifício, e que aconteceu entre 16 e 22 de maio de 2016. Contando com o apoio da bibliotecária Helena Tiomi O. Pitton, chefe da Biblioteca da Fatec SP, esta me mostrou uma fotografia, sem data ou notação de origem (Figura 4), informando tratar-se da aula inaugural do Centro Estadual de Educação Tecnológica São Paulo, segundo a sua antecessora.

A importância do centro de memória dispor desse documento histórico, que é a "Aula inaugural do Centro Estadual de Educação Tecnológica”, proferida pelo Governador Roberto de Abreu Sodré, em 03 de agosto de 1970, permitiu confirmar que o registro iconográfico apresentado na Figura 4, refere-se ao evento histórico de criação do Centro Paula Souza. Este documento também apresenta as intenções do governo do estado quanto à formação profissional dessa nova profissão, que é o tecnólogo. Segundo Roberto de Abreu Sodré (1970),

\footnotetext{
${ }^{1}$ Conselho de Defesa do Patrimônio Histórico, Arqueológico, Artístico e Turístico. CONDEPHAAT. http://www.cultura.sp.gov.br/.../menuitem.bb3205c597b9e36c3664eb10e2308 Acesso: 12 mai. 2015.

${ }^{2}$ http://www.cpscetec.com.br/memorias/arquivos/14_ibram.pdf. Acesso em: 21 dez. 2019.
} 
FIGURA 4 - Evento comemorativo de inauguração do Centro Estadual de Educação Tecnológica na Federação das Indústrias do Estado de São Paulo, s/d.

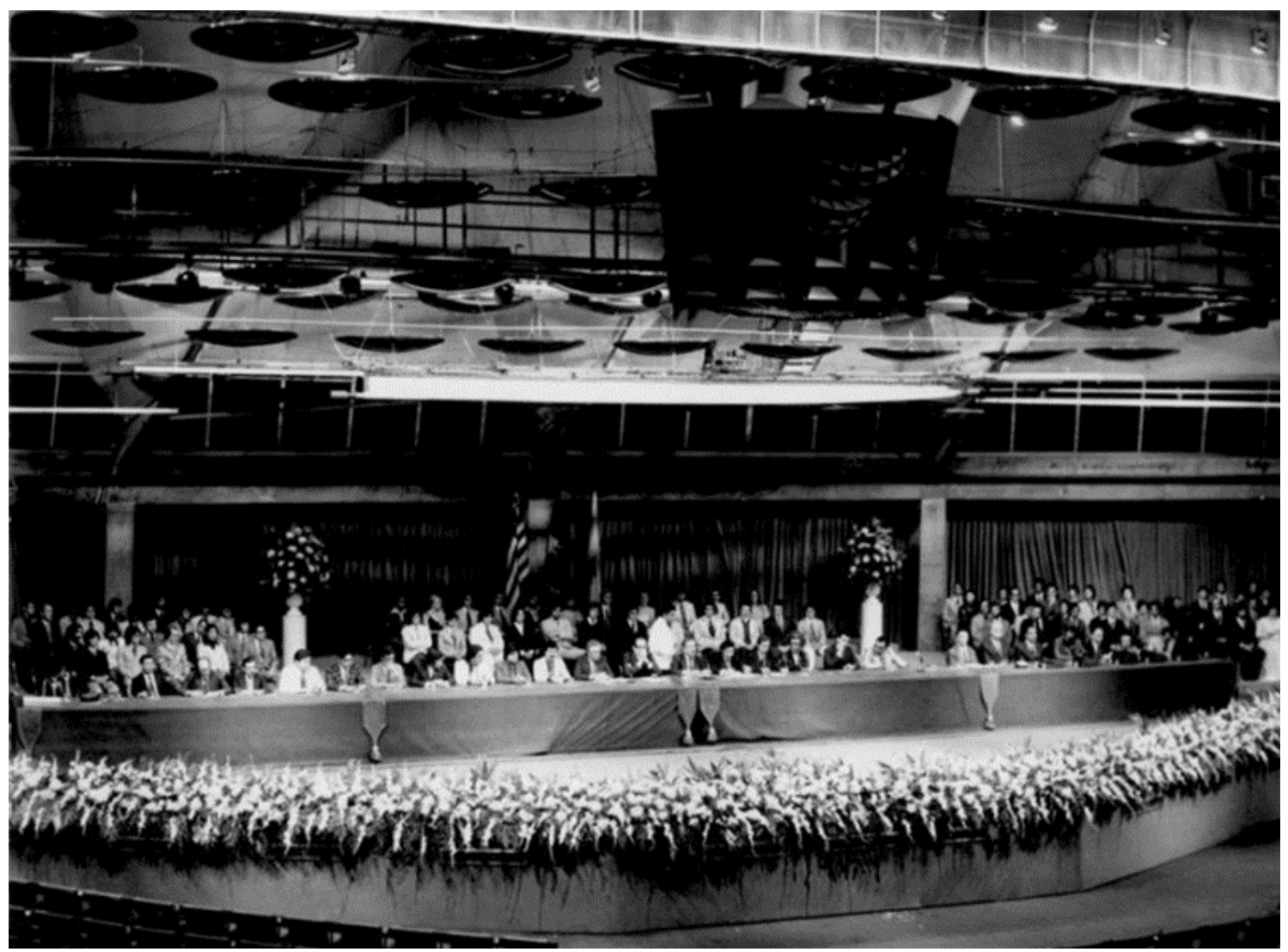

Fonte: Biblioteca da Faculdade de Tecnologia de São Paulo.

Fotografia: Maria Lucia Mendes de Carvalho, em 6 de maio de 2016.

O governador vê com grande esperança o Centro Estadual de Educação Tecnológica, não só por isso, mas também porque ele está juridicamente capacitado, e está se aparelhando eficazmente, para ajudar a preencher outras lacunas, aqueles vazios que aumentam em extensão à medida que queremos levar a formação profissional a parcelas cada vez mais numerosa da coletividade trabalhadora. Deverá o centro, segundo sua lei de criação, avançar pelo terreno do ensino técnico de segundo ciclo, preocupação constante dêste governo, que deseja habilitar para o trabalho a enorme parcela da juventude que fica à margem do Ensino Universitário. [...] O Centro se iniciou nos setores de Tecnologia Mecânica e de Construção Civil porque pareceu, a quem delegou a tarefa de concretizá-lo, a maneira mais segura de começar a experiência. [...] Há, assim, um vasto território a explorar no Ensino Técnico Superior, como o relacionado com o melhor aproveitamento de terra e dos produtos agrícolas; irrigação; drenagem; construções rurais; construções municipais; técnicas de transformação de produtos agrícolas perecíveis em produtos industrializados, favorecendo a iniciativa de pequenos produtores autônomos. Há depois, o preparo daqueles que vão trabalhar nas atividades terciárias, nos serviços de todos os tipos. Tais serviços

Rev. Iberoam. Patrim. Histórico-Educativo, Campinas (SP), v. 5, p. 1-10, e019040, 2019. 
precisam ser feitos por pessoal competente e conhecedor do ofício. (SODRÉ, 1970, p. 14-5)

Quanto a proposição dos cursos “Técnico Superior” e das elaborações de seus currículos no Centro Estadual de Educação Tecnológica, o engenheiro civil José Augusto Martins, professor titular de hidráulica aplicada na EPUSP entre 1967-1986, informou durante uma entrevista para a produção da obra comemorativa dos 25 anos de Centro Paula Souza (MOTOYAMA, 1995, p. 181 - 194) que:

O conselho designou a mim e a Octávio Ricardo para fazermos o plano inicial de cinco cursos na área de engenharia civil e de engenharia mecânica. Eu, pessoalmente, fui responsável pela minuta dos três cursos da engenharia civil: edificações, obras hidraúlicas e movimento de terra e pavimentação. Os cursos da área de mecânica eram desenho e projetos, que foram detalhados pelo prof. Octávio Ricardo. Naquele tempo se fixou a orientação de que deveriam ser contratados docentes que tivessem capacidade didática, mas que tivessem também alguma ligação com a atividade prática, fosse em execução de obras civis, fosse ligada à indústria, no planejamento ou no desenvolvimento industrial. Esses cinco cursos foram imediatamente implantados, e, no mesmo ano, fins de 1969, foi dado uma aula magna pelo próprio governador do estado. Essa aula aconteceu no recinto da Federação das Indústrias do Estado de São Paulo. (MOTOYAMA, 1995, p. 186)

Em 15 de março de 2016, empregando como metodologia de pesquisa a história oral, busquei informações sobre a ocupação do Edifício Paula Souza para implantar os cursos de tecnologia, entrevistando no Centro de Memória da Educação Profissional e Tecnológica para o projeto "História oral na educação: memórias do trabalho docente", o tecnólogo e engenheiro operacional João Honorato Jr. (Figura 5), que é professor da Etec Basilides de Godoy, e foi aluno da primeira turma de mecânica no Centro Estadual da Educação Tecnológica São Paulo. Durante a entrevista o professor informou que estudou:

Por incrivel que pareça, primeira turma da Fatec. Ingressei aqui na Fatec, mas precisamente no mês de agosto de 1970, na modalidade na época Oficina, e hoje é Processos Industriais. Acabei me formando, e para fazer das coincidências, nossa última aula foi em 13 de maio de 1972, quando a gente falou que era a libertação dos escravos. Porque o curso, na época, era um curso quadrimestral, contínuo, e a gente tinha que fazer o curso em dezoito meses. Ingressei no trabalho logo que me formei [...] Nós, junto com o professor Walter Cristian, o curso não era conhecido. Nós fizemos um trabalho de divulgação, o pessoal da Mecânica, onde nós fizemos um portifólio para divulgar o curso, entregando de mãos em 
mãos: - nossa capacidade, - nossa formação profissional, que até então era desconhecida. E a denominação na época era de Técnico de nível Superior. Infelizmente, esse pessoal não tinha essa cultura de tecnólogo, e desse trabalho que fizemos, levando os currículos, começaram a surgir praticamente de imediato algumas oportunidades. (HONORATO JR, 2016)

FIGURA 5 - João Honorato Jr. em entrevista de história oral sobre memórias do trabalho docente.

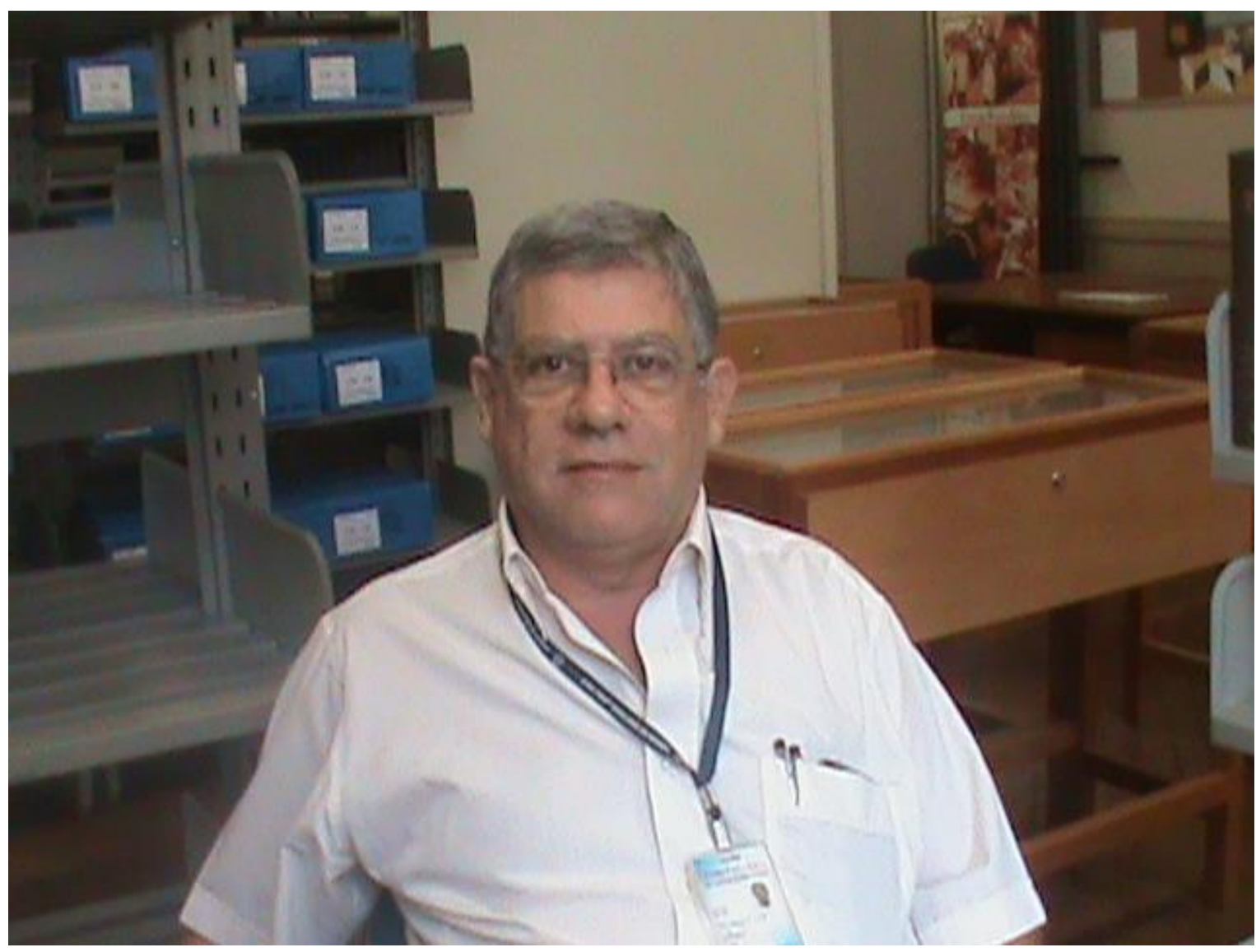

Fonte: Centro de Memória da Educação Profissional e Tecnológica do Centro Paula Souza. Fotografia: Maria Lucia Mendes de Carvalho, em 15/03/2016.

Para finalizar sobre a importância desse documento da Aula Inaugural para a história institucional do Centro Paula Souza, é necessário destacar que a sua primeira denominação Centro Estadual de Educação Tecnológica São Paulo (CEETSP), instalado em 1970 no Edifício Paula Souza, passou a Centro Estadual de Educação Tecnológica Paula Souza, em 1973, durante uma reorganização institucional, considerando as duas faculdades de tecnologia existentes no período, 
a Fatec de São Paulo ${ }^{3}$ e a Fatec de Sorocaba ${ }^{4}$, criadas por decretos, mas cujas origens estão relacionadas com a discussão e a implantação do CEETSP, e que já foram temas de teses de doutoramento, como a de Lauro Carvalho de Oliveira , "Faculdade de Tecnologia de Sorocaba: da gênese à consolidação", na UNISO, em 2014, e a de Lincoln Taira, "Relações históricas no universo da FATEC SP: técnica-tecnologia e educação", na FFLECH-USP, em 2005, localizada na Biblioteca da Fatec SP, em 2016.

Quanto a escolha do nome de Antonio Francisco de Paula Souza como patrono, segundo Motoyama (1995, p. 475): "Essa ideia ressurgiu no Conselho Deliberativo, já que o Centro estava localizado num prédio que era denominado Paula Souza e onde funcionava uma instituição fundada por ele (a Escola Politécnica de São Paulo)". Considero que Antonio Francisco de Paula Souza, como patrono de um Centro Estadual de Educação Tecnológica cinquentenário, muito bem o representa como profissional atuante que foi em vários campos dos saberes. Enquanto diretor da Escola Politécnica de São Paulo, na colação de graus dos formandos de 1899, Padilha (2010, p. 110) declara que Paula Souza "deixa muito claro mais uma vez sua preferência pelo ensino tecnológico":

Todavia, se tivéssemos de optar entre uma instrucção meramente scientifica e uma educação technica empírica, senhores, eu francamente vos declaro que optaria por esta última.

Antônio Francisco de Paula Souza nasceu em Itu, em uma família de estadistas e políticos, em 6 de dezembro de 1843. Foi aprimorar seus estudos, com doze anos, em Dresden na Alemanha. Retornou ao Brasil, dois anos depois, e no ano seguinte, parte para Zurique com a intenção de ingressar na Escola Politécnica. Inicia seus estudos na engenharia, mas dois anos depois, ingressa no curso de filosofia, o que lhe traz muitos problemas. Deixa Zurique, e em 1865, matricula-se na Faculdade de Engenharia Civil de Karlsruhe, na Alemanha, mas não conclui o curso e retorna ao Brasil, em 1867.

Quando retorna da Alemanha assume a direção da Repartição de Obras Públicas em São Paulo. Em 1872, entra para a maçonaria, em seguida, participa da fundação do Partido Republicano Paulista (PRP) e, como chefe da Seção de estudos e construção da estrada de ferro Itu e Rio Claro, publica "Estradas de Ferro na Província de São Paulo". Dez anos, depois, lidera o projeto de

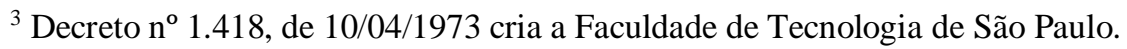

${ }^{4}$ Decreto-lei no 243 , de 20/05/1970 cria a Faculdade de Tecnologia de Sorocaba.
} 
construção de outra estrada de ferro, Rio Claro-São Carlos, e em 1890, é o primeiro diretor da Superintendência de Obras Públicas do Estado de São Paulo.

Entre 1892 e 1994, Antonio Francisco de Paula Souza foi eleito Deputado Estadual do PRP, assumindo dois ministérios nesse período. O primeiro, Ministro dos Negócios Estrangeiros, e o segundo, Ministro da Indústria, Viação e Obras Públicas. Durante a sua carreira publicou várias obras sobre

Construção Civil, tornando-se membro da primeira diretoria provisória do Instituto de Engenharia, em 1916. Faleceu, em São Paulo, no dia 14 de abril de 1917, em sua residência preparando aulas.

Em 1973, ao rebatizar a instituição como Centro Estadual de Educação Tecnológica Paula Souza, oferecendo cursos tecnológicos nas Faculdades de Tecnologia de São Paulo e de Sorocaba, foi uma justa homenagem a esse professor emérito da Escola Politécnica.

Neste ano, que comemoramos o cinquentenário do Centro Paula Souza (CPS), uma autarquia do Governo do Estado de São Paulo, vinculada à Secretaria de Desenvolvimento Econômico, é preciso detacar que a premonição do governador Abreu Sodré na Aula Inagural quanto ao avanço do ensino técnico proposto desde a criação dessa instituição, aconteceu, conforme demonstram os dados apresentados na Tabela 1.

TABELA 1 - Evolução do número de unidades de escolas técnicas e de faculdades de tecnologia.

\begin{tabular}{|c|c|c|c|c|c|c|c|c|}
\hline CPS & $\mathbf{1 9 6 9}$ & $\mathbf{1 9 7 9}$ & $\mathbf{1 9 8 9}$ & $\mathbf{1 9 9 4}$ & $\mathbf{1 9 9 9}$ & $\mathbf{2 0 0 9}$ & $\mathbf{2 0 1 4}$ & $\mathbf{2 0 1 9}$ \\
\hline Etec & 0 & 0 & 14 & 99 & 99 & 167 & 218 & 223 \\
\hline Fatec & 1 & 2 & 4 & 6 & 9 & 49 & 63 & 73 \\
\hline
\end{tabular}

Fonte: Centro de Memória da Educação Profissional e Tecnológica do Centro Paula Souza.

É preciso dar destaque neste cinquentenário, ao fato do Centro Paula Souza estar presente em 322 municípios, formando mais de 294 mil alunos em cursos técnicos de nível médio e superiores tecnológicos, e, desde 2004, sob a direção da superintendente Laura Laganá. Nas escolas técnicas (Etecs) o número de matriculados ultrapassa 208 mil estudantes nos Ensinos Técnico, Médio e Técnico Integrado ao Médio, incluindo habilitações nas modalidades presencial, semipresencial, online, Educação de Jovens e Adultos (EJA) e especialização técnica. As Etecs oferecem 151 cursos, voltados a todos os setores produtivos públicos e privados. Enquanto que, nas faculdade de tecnologia (Fatecs) estas atendem mais de 85 mil alunos matriculados em 77 cursos de graduação tecnológica, em diversas áreas, como Construção Civil, Mecânica, 
Informática, Tecnologia da Informação, Turismo, entre outras. Além da graduação, o Centro Paula Souza oferece cursos de pós-graduação, atualização tecnológica e extensão (CENTRO PAULA SOUZA, 2019).

Com o apoio do coordenador Almério Melquíades de Araújo, da Unidade de Ensino Médio e Técnico, e da coordenadora Helena Gemignani Peterossi, da Unidade de Pós-graduação, Pesquisa e Extensão, informo que o Centro de Memória da Educação Profissional e Tecnológica, que hoje recebe consulentes com visitas agendas, a partir de fevereiro de 2020, será mantido aberto ao público, um dia por semana, a fim de possibilitar estudos e pesquisas no acervo por estudantes, docentes e pesquisadores internos e externos a instituição.

\section{REFERÊNCIAS}

CARVALHO, Maria Lucia Mendes de. Arquivo Histórico Institucional: a importância para a história da educação profissional e tecnológica no Centro Paula Souza. In: CARVALHO, Maria Lucia Mendes de (org.). Coleções, Acervos e Centros de Memória. São Paulo: Centro Paula Souza, 2017, p. 39-58. Disponível em: http://www.cpscetec.com.br/memorias/arquivos/colecoesImprensaOficial13abr2017Nanci.pdf. Acesso em: 21 dez. 2019.

CENTRO PAULA SOUZA. Quem somos. Disponível em: https://www.cps.sp.gov.br/sobre-ocentro-paula-souza/. Acesso em: 23 dez. 2019.

HONORATO JR., José. Entrevista concedida a Maria Lucia Mendes de Carvalho no Centro de Memória da Educação Profissional e Tecnológica, em 15 de março de 2016. Disponível em: http://www.memorias.cpscetec.com.br/historiaoraldocVer.php?cma=21\&vol=3. Acesso em: 23 dez. 2019.

MOTOYAMA, Shozo (org.). Educação Técnica e Tecnológica em Questão. 25 anos do CEETEPS. Uma história vivida. São Paulo: Editora da UNESP: CEETEPS, 1995.

OLIVEIRA, Lauro Carvalho. Faculdade de Tecnologia: da Gênese à Consolidação. 2014. 257p. Tese (Programa de Pós-Graduação em Educação) Universidade de Sorocaba, em Sorocaba. Disponível no site: http://www.memorias.cpscetec.com.br/publicacoes/dissertacao/TeseLauroCarvalhodeOliveiraFat ecSorocaba.pdf. Acesso em: 23 dez. 2019.

PADILHA, Rodrigo Bastos. Antonio Francisco de Paula Souza. Engenheiro, Político e Educador. Criador da Escola Politécnica de São Paulo. $1^{a}$ Ed. - São Paulo: Leopardo Editora. 2010. 137p. 
SODRÉ, Roberto de Abreu. Desenvolvimento e Educação Tecnológica. Aula Inaugural do Centro Estadual de Educação Tecnológica. São Paulo: Tipografia Edanee S. A. 1970. 24p. Disponível em:

http://www.cpscetec.com.br/memorias/livros/memorias/AulainauguralCPSgovAbreuSodre1970.p df. Acesso em: 21 dez. 2019.

TAIRA, Lincoln. Relações históricas no universo da FATEC SP: técnica-tecnologia e educação. 2005. 142p. Tese (Doutorado no Programa de Pós-Graduação em História Social, do Departamento de História). Faculdade de Filosofia, Letras e Ciências Humanas da Universidade de São Paulo, em São Paulo.

Recebido em: 24 de dezembro de 2019 Aceito em: 27 de dezembro de 2019 